\title{
Borderline symptoms and suicidality/self-injury in late adolescence: Prospectively observed relationship correlates in infancy and childhood
}

\section{Citation}

Lyons-Ruth, Karlen, Jean-Francois Bureau, Bjarne Holmes, Ann Easterbrooks, and Nancy Hall Brooks. 2013. "Borderline Symptoms and Suicidality/self-Injury in Late Adolescence: Prospectively Observed Relationship Correlates in Infancy and Childhood." Psychiatry Research 206 (2-3) (April): 273-281. doi:10.1016/j.psychres.2012.09.030.

\section{Published Version}

doi:10.1016/j.psychres.2012.09.030

\section{Permanent link}

http://nrs.harvard.edu/urn-3:HUL.InstRepos:37140320

\section{Terms of Use}

This article was downloaded from Harvard University's DASH repository, and is made available under the terms and conditions applicable to Other Posted Material, as set forth at http:// nrs.harvard.edu/urn-3:HUL.InstRepos:dash.current.terms-of-use\#LAA

\section{Share Your Story}

The Harvard community has made this article openly available.

Please share how this access benefits you. Submit a story. 


\title{
Borderline Symptoms and Suicidality/Self-injury in Late Adolescence: Prospectively Observed Relationship Correlates in Infancy and Childhood
}

\author{
Karlen Lyons-Ruth ${ }^{\mathrm{a},{ }^{*}}$, Jean-Francois Bureau ${ }^{\mathrm{a}, \mathrm{b}}$, Bjarne Holmes $^{\mathrm{a}, \mathrm{c}}$, Ann Easterbrooks ${ }^{\mathrm{d}}$, and \\ Nancy Hall Brooks ${ }^{a, e}$ \\ ${ }^{a}$ Cambridge Hospital, Department of Psychiatry, Harvard Medical School, 1493 Cambridge \\ Street, Cambridge, MA 02139, United States \\ bSchool of Psychology, University of Ottawa, Ottawa, Ontario, Canada \\ 'School of Life Sciences, Herriot-Watt University, Edinburgh, UK \\ dEliot-Pearson Department of Child Development, Tufts University, Medford, Massachusetts, \\ USA
}

eDepartment of Psychiatry, Harvard Medical School, McLean hospital, Belmont MA

\begin{abstract}
The primary objective was to assess whether prospectively observed quality of parent-child interaction in infancy and middle childhood contributed to the prediction of borderline symptoms and recurrent suicidality/self-injury in late adolescence. Adolescents (mean 19.9 years) from 56 families participating in a longitudinal study since infancy (retention rate 74\%) were assessed on the SCID-II for symptoms of borderline personality disorder, including suicidality/self-injury. Early clinical risk was indexed by clinical referral to parent-infant services. Attachment security and parent-child interaction were assessed from videotape at 18 months and 8 years. Severity of childhood abuse was rated from interview and self-report measures. Maternal withdrawal in infancy was a significant predictor of both borderline symptoms and suicidality/self-injury in late adolescence. Disorganizedcontrolling child behavior at age 8 contributed independently to the prediction of borderline symptoms. The effect of maternal withdrawal was independent of, and additive to, variability explained by severity of childhood abuse. Borderline symptoms and suicidality/self-injury may be preceded developmentally by disturbed interactions as early as 18 months of age. A parent-child transactional model is proposed to account for the findings.
\end{abstract}

\section{Keywords}

Borderline personality disorder; Suicide; Longitudinal; Attachment; Maltreatment

\footnotetext{
(C) 2012 Elsevier Ireland Ltd. All rights reserved.

*Corresponding author. Tel.: +1 617503 8470; fax: +1 617547 3116. klruth@ hms.harvard.edu.
}

Publisher's Disclaimer: This is a PDF file of an unedited manuscript that has been accepted for publication. As a service to our customers we are providing this early version of the manuscript. The manuscript will undergo copyediting, typesetting, and review of the resulting proof before it is published in its final citable form. Please note that during the production process errors may be discovered which could affect the content, and all legal disclaimers that apply to the journal pertain. 


\section{Introduction}

Borderline personality disorder (BPD) is characterized by impulsive, self-damaging behavior, often including recurrent suicidal or self-injuring behaviors (American Psychiatric Association, 2000). BPD is associated with a high rate of hospitalization and a mortality rate of up to $10 \%$ (Gross et al., 2002; Skodol et al., 2002). BPD has an incidence of 1 to $2 \%$ (Torgersen et al., 2001), and a lifetime prevalence of up to 6\% (Grant et al., 2008).

Recurrent suicidality is even more prevalent, with $16.9 \%$ of adolescents considering suicide and $8.5 \%$ making an attempt (Kessler et al., 1999). The prevalence of non-suicidal selfinjury is also high, with rates of $38 \%$ to $67 \%$ in clinical samples and rates of $10 \%$ to $44 \%$ in community samples (Heath, et al., 2009). Little is known about developmental processes associated with BPD and suicidality/self-injury. In studies of adults, a number of factors have been associated concurrently with BPD. For example, individuals with BPD symptoms often come from families at greater socioeconomic risk (Cohen et al., 2008). Comorbidity with Axis I disorders is also common, particularly depression (Skodol et al., 2002; Grant et al., 2008). While clinical studies have found BPD to be more frequent among females (Lieb et al., 2004), community samples have not consistently replicated this finding (Bernstein et al., 1993; Torgersen et al., 2001; Lenzenweger et al., 2007). Genetic factors also play a role in suicidality and BPD (Torgersen et al., 2000; Anguelova et al., 2003). In addition, geneenvironment interactions indicate that environment may alter the expression of genetic factors related to suicide (Caspi et al., 2003). States of intense arousal to stressors characterize patients with BPD and suicidality/self-injury (Stiglmayr et al., 2001) and randomized animal models have established that poor quality caregiving can up-regulate the expression of genes related to stress reactivity (Francis et al., 1999; Barr et al., 2003). Therefore, early family factors contributing to the development of borderline symptoms are important to identify, as they may have the potential to affect gene expression related to stress reactivity. However, family factors have been studied primarily through retrospective self report. Self-report studies have repeatedly indicated that BPD is associated with childhood maltreatment (e.g. Horesh et al., 2008; Zanarini et al., 1997). In addition, using a prospective design, Widom et al. (2009) found an increased incidence of BPD among young adults with documented early abuse histories. However, when abuse is noted, this is often only the tip of the iceberg and indexes pervasive difficulties in the family in establishing caregiving routines, managing anger, establishing appropriate discipline, and having appropriate expectations for child behavior, as well as in protecting the child (Bradley et al., 2005; Fassler et al., 2005). Thus, we see disturbances in ongoing family interaction as a frequent correlate of abuse, but one that may also have an impact independent of abuse events because these disturbances are not episodic events but are a part of the minute-tominute fabric of interaction.

Many theorists have offered formulations concerning ongoing deviations in parent-child interaction likely to be associated with BPD symptoms (Linehan, 1993; Gunderson, 1996; Fruzzetti et al., 2005; Fonagy and Luyten, 2009). For example, Linehan (1993) has argued that 'emotionally invalidating' family environments during childhood coupled with a reactive temperament may lead to patterns of emotion dysregulation, including impulsive self-damaging behavior. However, these theories of developmental antecedents have rarely been operationalized clearly (e.g. what types of parental behavior would be considered invalidating ?) nor have they been approached with longitudinal designs and direct observations of problematic parent-child interactions.

Insecure or disorganized attachment relationships, which have been extensively operationalized and assessed longitudinally (e.g. van IJzendoorn et al., 1999), have also been proposed as a vulnerability factor predisposing a child to unregulated arousal, suicidality, and borderline symptoms (Levy, 2005; Gunderson and Lyons-Ruth, 2008; Fonagy and 
Luyten, 2009). Further, Denham (1998) has speculated that attachment figures have a greater role in the socialization of emotion regulation and expression during the first two years of life compared to later developmental periods. Empirical evidence for the particular importance of stressors during the first years of life is beginning to accrue. For example, both Dearing and colleagues (2006) and Brooks-Gunn and colleagues (2005) have found that poverty in the first five years of life is associated with more deleterious long-term outcomes than poverty later in childhood. Bureau, Easterbrooks, and Lyons-Ruth (2009a) found that maternal depression in the first two years of life contributes to adolescent depression independently of maternal depression at later ages. Disorganized attachment behavior by the infant is characterized by the lack of a consistent strategy for gaining comfort from the caregiver and is associated with elevated cortisol to stressors in infancy (e.g. Spangler and Grossmann, 1993; Hertsgaard et al., 1995). Disorganized infant attachment behavior also predicts behavior problems in childhood and dissociative symptoms in adolescence (Carlson, 1998; van IJzendoorn et al., 1999). Infant disorganized attachment behavior has been repeatedly associated with the caregiver's atypical responses to infant cues, including unavailability to respond to infant fear or distress, as well as frightened or frightening behavior toward the infant (for review, see Lyons-Ruth and Jacobvitz, 2008). Such frightened, frightening or atypical parental responses to child cues can be reliably assessed and are stable for periods up to five years (Madigan et al., 2006). Therefore, both caregiver and infant components of disorganized attachment relationships are important to assess in pathways to BPD symptoms.

Over the preschool years, disorganized behavior often transforms into controlling behavior toward the parent (Main and Cassidy, 1988; NICHD ECCRN, 2001; Moss et al., 2005). These controlling behaviors are manifest in either a caregiving or a punitive fashion. Controlling-punitive behavior consists of attempts to assert authority over the parent using harsh commands or belittling comments. Controlling-caregiving behavior consists of directing the parent's activities by guiding, encouraging, or structuring the parent. However, one third of disorganized infants do not adopt a controlling attachment pattern by age six but continue to show odd, out-of-context (disorganized) behaviors in the presence of the parent (Moss et al., 2005). Among families to be reported on here, Bureau, Easterbrooks, and Lyons-Ruth (2009b) found that children who displayed disorganized behavior in infancy were more likely to exhibit punitive and disorganized behavior at age 8 , but only among families with clinical risk factors. Children who had experienced more maternal withdrawal in infancy were more likely to show caregiving behavior at age eight regardless of family risk. Controlling or disorganized behavior in preschool has also been associated with childhood behavior problems (van IJzendoorn et al., 1999; Moss et al., 2006; O'Connor et al., 2011). However, to date, no studies have assessed the relevance of disorganizedcontrolling attachment behaviors for later borderline symptoms and suicidality. Among the few prospective studies, two studies have used community survey data to confirm the longitudinal association between childhood abuse and BPD symptoms (Johnson et al., 1999; Widom et al., 2009). However, Crawford et al. (2009) noted that structured observations of parent-child interactions would strengthen the validity of these assessments. Only one prospective study has included such structured observations (Carlson et al., 2009). In that study, maternal hostility at age 3, maternal self-reported life stress, and child selfrepresentation significantly and uniquely predicted BPD symptoms. Other factors, including infant disorganized attachment and maternal boundary dissolution at age 3 , did not add to prediction once the above factors were considered.

This study did not report on assessments of mother-infant interaction between 6 months and three years of age, and did not assess child attachment behavior after infancy. In addition, no study has yet evaluated whether the quality of observed parent- child interaction adds to prediction beyond the prediction associated with abuse experiences. Finally, previous work 
has not assessed whether parent-child disturbed interactions at different developmental periods (infancy, childhood) make independent contributions to prediction of BPD symptoms or whether disturbance in infancy is only problematic if it leads to continued disturbance later in childhood. These are the questions addressed in the current study.

\subsection{Objectives}

The present study evaluated the contributions of quality of observed parent-child interaction in both infancy (18 mos.) and middle childhood (eight yrs.), as well as the contribution of severity of abuse, to the prediction of borderline symptoms in late adolescence (age 20). Participants were fifty-six families who had been participating in a longitudinal study since infancy. The two outcomes of interest included 1) the extent of borderline symptoms on the SCID-II, and 2) the presence, in particular, of the borderline symptom of recurrent suicidality/self-injury. This symptom accounts for a large proportion of public health resources, whether or not other borderline symptoms are present, and deserves independent assessment.

The first aim was to assess whether prospectively observed quality of mother- child interaction in infancy was predictive of overall borderline symptoms, or of suicidality/selfinjury specifically, in late adolescence. A secondary aspect of this aim was to examine whether reliable laboratory ratings captured (mediated) any prediction associated with clinical observations in infancy. The second aim of the study was to evaluate whether the quality of early parent-infant interaction had an independent effect on the two adolescent outcomes or whether any effects were mediated through a relation to later childhood abuse. The third aim was to assess whether earlier forms of disturbed interaction exerted an effect on outcomes through their relation to later forms of disturbed interaction or whether both early and later forms of interaction had independent effects on outcomes. The fourth aim of the study was to evaluate whether disorganized-controlling behavior had an independent effect on adolescent outcomes, or whether its effects overlapped with effects related to childhood abuse. The final aim was to evaluate whether parent-child observations at different developmental periods made independent and additive contributions to prediction or whether disturbed interaction in infancy was predictive primarily because it predicted further disturbance at age eight (mediated model).

\section{Methods}

\subsection{Participants}

Participants were 56 low-income families seen when the child was in late adolescence (m. 19.7 yrs.; range $18-23$ yrs.; female $=41 \%$ ). Families were participants in a longitudinal study of child adaptation since infancy (18 months). Seventy-three percent of families were non-Hispanic Caucasian, 27\% Hispanic or African-American. In infancy, income of all families was $<=200 \%$ poverty level. In adolescence, $71 \%$ of families had incomes $<=$ $\$ 40,000$. The 56 families were part of an original cohort of 76 families seen in infancy. In late adolescence, $14 \%$ (11) could not be relocated; 11\% (7) refused; and 3\% (2) lived overseas, yielding a retention rate of $74 \%$ (56). Families followed up in adolescence did not differ from those not followed up on socioeconomic indicators, gender, age, clinical status, or infant/childhood outcome assessments (effect sizes $(\varphi, \eta$, or $\tau)=-0.15-0.16)$. All procedures were approved by the Institutional Review Board. Written informed consent was obtained from parent and adolescent.

\subsection{Measures}

2.2.1. Borderline symptoms and suicidality/self-injury-Number of borderline symptoms and presence of recurrent suicidality/self-injury (BPD Criterion 5) were assessed 
for the adolescent participants using the Structured Clinical Interview for DSM-IV-R (SCID) for Axis II, administered by trained clinicians (First at al., 1997a). Presence of major depressive episodes was assessed on the SCID-I (First et al., 1997b). The SCID yields reliability kappa's of 0.61 for current diagnosis and 0.68 for lifetime diagnoses, comparable to other structured diagnostic interviews.

2.2.2. Severity of childhood abuse-A 7-point rating for severity of abuse from birth to age 18 (reliability $r_{\mathrm{i}}=0.99 ; n=37$ ) was assigned by reviewing responses to three abuse assessments administered in late adolescence: the Conflict Tactics Scale- $2^{\text {nd }}$ version (CTS-2: Straus et al., 1998), the Childhood Traumatic Experiences Scales-Revised (CTESR, Dutra et al., 2005), and the Traumatic Stress Schedule (TSS: Norris, 1990). State protective services involvement and placement in foster care between 0-18 years were assessed from maternal interviews. The CTS-2 is a widely used 78-item measure of tactics used during conflict between family members. Tactics include physically abusive behavior and emotionally abusive behavior, e.g. "My parent hit or kicked me; my parent insulted or swore at me." The overall scale has a stable factor structure, moderate test-retest reliability, and demonstrated validity (Straus et al., 1996, Straus et al., 1998). The CTES-R consists of four 5-point scales for rating the severity of physical abuse, sexual abuse, verbal abuse and witnessed interpersonal violence on the Adult Attachment Interview (AAI). The AAI is a semi-structured, transcribed, one-hour interview that asks participants in detail about attachment-related experiences with primary caregivers. Reliability on the four scales was $r_{\mathrm{i}}$ $=0.89-0.98$ (two raters; $n=56$ ). The TSS is an eight-question narrative survey probing traumatic experiences. Responses to the three TSS questions on experiences of sexual or physical assault were also reviewed in making the abuse rating.

2.2.3. Early clinical risk (1-18 months) -In infancy, $52 \%$ of families had been referred for parent-infant clinical services during the first year of life due to concerns about the quality of parental care. The other $48 \%$ of families had not been referred for problems in care. Absence of problems in the non-referred group was further screened by a one-hour observation at home by study clinicians.

Eight referred families were also being followed by state protective services for diverse indicators of infant risk, including documented poor care $(n=2)$, previous maltreatment of an older sibling $(\mathrm{n}=1)$, or maternal psychiatric disturbance or substance abuse $(\mathrm{n}=5)$. In no instance had the infant been physically or sexually abused.

2.2.4. Infant attachment security (18 months)-Mothers and infants were videotaped in the Strange Situation Procedure at 18 months of age (Ainsworth et al., 1978). The infant is videotaped in a playroom during a series of eight structured 3-min episodes in which the mother leaves and rejoins the infant twice. The procedure is designed to be mildly stressful in order to activate the infant's attachment behavior. Videotapes were reliably coded for secure, insecure and disorganized attachment behaviors as previously reported (Lyons-Ruth et al., 1990). Following earlier precedent, security of attachment was indexed by a threelevel ordinal variable ( $1=$ secure; $2=$ insecure-organized; 3 =insecure-disorganized). The attachment distribution in infancy was Secure 31\%; Insecure-Organized 16\%; Disorganized $53 \%$.

2.2.5. Disrupted mother-infant communication ( 18 months)—Disrupted maternal communication was coded from videotapes of the Strange Situation Procedure by coders naïve to all other data, using the AMBIANCE coding system (Lyons-Ruth et al, 1999). Frequencies of five classes of disrupted maternal communication are coded: a) affective communication errors, b) role confusion, c) negative-intrusive behavior, d) disorientation, 
and e) withdrawal. Reliability between two coders $(n=15)$ ranged from $r_{\mathrm{i}}=0.73-0.84$. Validity and stability of the AMBIANCE have been established by meta-analysis ( $N$ s of 384 and 203) (Madigan et al., 2006).

2.2.6. Child disorganized-controlling behavior ( 8 years)—Parent and child were videotaped in a standard 5-minute reunion after a one-hour separation (Main and Cassidy, 1988). Videotapes were coded using the Middle Childhood Disorganization and Control scales (MCDC) (Bureau et al., 2009b) to rate the extent (1-9) of controlling-punitive, controlling-caregiving, and behaviorally disorganized interaction with the parent. All codes were reliable $\left(r_{\mathrm{i}}=0.83-0.97 ; n=22\right)$; coders were naïve to all other data. These three aspects of behavior are not mutually exclusive and children can be elevated on more than one scale. Therefore, a three- level variable was created to capture overall disorganized-controlling behavior, with $1=$ low on all three ratings of disturbed behavior (all ratings $<3$ ); $2=$ elevated on only one rating; 3 = elevated on two or three of the ratings.

\subsection{Analytic procedures}

To test Aims 1, 3, and 4, separate linear (number of borderline symptoms) or logistic (presence of recurrent suicidality/self-injury) regression models were calculated (Cohen et al., 2003), controlling for gender and major depressive disorder, using SPSS Version 19 software. For Aims 2 and 5, mediation was tested using bootstrapped confidence intervals, which is now the preferred method of analysis for mediation (Dearing and Hamilton, 2006). Preacher and Hayes' (2008) INDIRECT macro for SPSS Version 19 was used to estimate the total, direct, and indirect effects of predictor variables on outcomes through the proposed mediators. For all aims, multiple imputation was employed to estimate missing data, following recommendations of Schafer and Graham (2002). Missing data were imputed using the Markov Chain Monte Carlo procedure (Gilks et al., 1996) in SAS software. The percentages of missing data ranged from $0-39 \%$, with a total missing rate of $14.1 \%$. This range is well within the recommended allowances for imputation procedures and imputation is strongly recommended over analysis of the raw data alone (Schafer and Graham, 2002; McCartney et al., 2006). In the present study, 10 data sets were generated with excellent efficiency (power to detect a significant effect of 97\%) according to Rubin's (1987) guidelines. Results with missing data imputed and results without imputation were similar.

\section{Results}

Descriptive data are presented first. Analyses for predictors of overall borderline symptoms are presented second, followed by analyses for predictors of suicidality/self-injury specifically.

\subsection{Prevalence of borderline symptoms, suicidality, and abuse}

The range of borderline symptoms was $0-5$ ( $m 0.96 ; S D=1.44) ; 41 \%$ met criteria for one or more symptoms; $2 \%$ met criteria for diagnosis. Among symptomatic adolescents, $53 \%$ ( $21 \%$ of the total sample) exhibited recurrent suicidal threats or self injury (DSM-IV Criterion 5) and 53\% exhibited two or more types of impulsive self-damaging behavior (DSM-IV Criterion 4); 89\% exhibited one of these two symptoms. In addition, 47\% met Criterion 2 for intense and unstable relationships. Other symptoms were less frequent and occurred only in the presence of one or more of the above symptoms.

Means and $S D$ 's of predictors are displayed in Table 1. Correlations among predictors are displayed in Table 2 . In initial analyses, borderline symptoms and suicidality were unrelated to age at assessment, gender, and socioeconomic indicators (family income, mother's education, mother's single parenthood, minority status) (effect sizes -0.22 to 0.18 , all $P n s$ ). 
However, because borderline symptoms have been consistently related to female gender in clinical samples (Lieb et al., 2004), gender was controlled in all analyses. Major depression was associated with borderline symptoms $(t(56)=2.62, P=0.01)$, so depression was also controlled in all analyses. By age 18 months, $14 \%$ were being followed by state protective services for poor quality care. By late adolescence, with self-report measures included in the assessments, $48 \%$ were found to have experienced sexual or physical abuse; another $7 \%$ reported severe verbal abuse only. Consistent with the literature, the severity of childhood abuse was significantly associated with the extent of borderline symptoms (Tables 2 and 3). However, severity of abuse was not a significant correlate of recurrent suicidality/self-injury alone (Table 6). Protective services involvement in infancy did not provide significant prediction of later borderline symptoms or suicidality/self-injury $(F \operatorname{chg}(1.53)=.23, n s$; Wald $(1,53)=.13$, ns, respectively).

\subsection{Observed interactions as predictors of borderline symptoms}

3.2.1. Clinical risk, interaction and attachment in infancy-The first aim was to assess whether mother- child interaction in infancy was predictive of adolescent outcomes. The set of seven infancy variables as a whole contributed significant prediction to later borderline symptoms $\left(F(6,47)=4.18^{* *}, P=0.007\right.$; Table 3$)$. Based on this overall finding, the seven predictors were examined individually. Early clinical risk, as indexed by clinical referral prior to 18 months of age, was a significant predictor of later borderline symptoms (Table 3). Of the five subtypes of disrupted communication, maternal withdrawal in infancy predicted more extensive borderline symptoms in adolescence (Table 3). Security of the infant's attachment behavior was not a significant predictor of borderline symptoms (Table 3). Thus, the quality of maternal caregiving behavior in infancy, both as assessed by clinicians and by laboratory observations, provided stronger prediction of later borderline symptoms than assessment of infant behavior alone.

While clinician referral to infant services has important ecological validity, it is difficult to know what prompted individual clinicians to make referrals to clinical services. Thus, we also evaluated whether clinicians' referred judgments prior to 18 months of age were related to borderline symptoms indirectly through their relation to observed maternal withdrawal at 18 months. A mediation analysis was conducted to test this hypothesis. While the total effect of clinical referral on borderline symptoms was significant as reported above (Table 3), after controlling for maternal withdrawal, the effect of clinical referral on borderline symptoms became non-significant $(\beta=0.14, t=1.11, P=0.27)$, consistent with a mediation hypothesis. Bootstrapped confidence intervals confirmed that clinical referral had a significant indirect effect on borderline symptoms through maternal withdrawal, because the bootstrapped confidence intervals did not contain zero (Table 4). This indirect effect suggests that clinician's judgments in infancy were predictive of borderline symptoms in part because clinicians were judging earlier maternal withdrawing behavior toward the infant as one basis for their referrals. Thus, maternal withdrawal to the infant's attachment cues emerged as the most important prospective predictor of later borderline symptoms.

\subsubsection{Assessment of severity of abuse as mediator of the effect of early} interaction-The second aim of the study was to evaluate whether the quality of early parent-infant interaction had a direct effect on borderline symptoms or whether its effects were mediated through a relation to later childhood abuse. In order to conduct such a mediation analysis, it must be plausible that the mediator (childhood abuse) occurred subsequent to the variable whose effects are being assessed for mediation (maternal withdrawal at 18 months). Because only eight families were being followed for maltreatment up to 18 months of age, and none of those had engaged in physical, sexual, or verbal abuse (only poor quality care), the assumption that physical, sexual, or verbal abuse 
experiences occurred subsequent to the maternal withdrawal observed at 18 months was supported by the data.

In the mediation model, maternal withdrawal was the independent variable, severity of abuse was the proposed mediator, and borderline symptoms was the dependent variable, with gender and depression as covariates. The significant correlation between early maternal withdrawal and later severity of abuse is shown in Table 2. After controlling for severity of abuse, the direct effect of maternal withdrawal on borderline symptoms remained statistically significant $(\beta=.40, t=2.85, P=.005$; Figure 1$)$. Bootstrapped confidence intervals confirmed that maternal withdrawal did not affect borderline symptoms indirectly through severity of abuse, because the bootstrapped confidence intervals for the estimated indirect effect contained zero (Table 4). The model that emerges is one in which two independent factors, maternal withdrawal in infancy and severity of later abuse, contribute separately to the extent of borderline symptoms.

\subsubsection{Observed child attachment behavior toward the parent in middle} childhood-The third aim of the study was to evaluate whether disorganized-controlling behavior in middle childhood was associated with later borderline symptoms. A linear regression model, controlling for gender and major depression, confirmed that disorganizedcontrolling behavior at age 8 was also a significant predictor of the extent of borderline symptoms at age 20 (Table 3). To illustrate this finding, we dichotomized the sample into those with and without borderline traits ( 2 or more symptoms). Among children who displayed combinations of disorganized and controlling behavior at age 8 (punitive, caregiving, disorganized), $43.5 \%$ displayed borderline traits in adolescence, compared to $15.3 \%$ of those elevated on only one scale, and none of those with low scores on all three scales. Thus, children with combinations of controlling and disorganized attachment behaviors at age 8 were more likely to display borderline symptoms in adolescence.

\subsubsection{Relations among severity of abuse, child disorganized-controlling behavior, and borderline symptoms-The fourth aim of the study was to evaluate} whether the effects of disorganized-controlling behavior and childhood abuse were independent and additive or whether one variable was accounting for most of the effect of the other variable on later borderline symptoms. Consistent with the possibility of overlap in prediction, children who had experienced more severe abuse were also more likely to display disorganized-controlling behavior (Table 2).

Because we could not establish the temporal ordering of childhood abuse experiences relative to the assessment of child disorganized-controlling behavior at age 8 , we did not conduct a mediation analysis. Instead, a standard regression analysis was conducted, with gender and depression entered on Step 1 as control variables and disorganized/controlling behavior in childhood and severity of abuse entered together on Step 2, with borderline symptoms as the dependent variable. Results indicated that, together, the two variables accounted for a significant and sizeable portion of variance in later borderline symptoms (Table 5, Step 2). However, with severity of abuse controlled, the effect of disorganized/ controlling behavior on borderline symptoms became only marginally significant $(\beta=0.27, t$ $=1.77, P=0.08$; compare Tables 3 and 5). Similarly, with child disorganized-controlling behavior controlled, severity of abuse failed to reach significance $(\beta=0.21, t=1.57, P=0.12$; compare Tables 3 and 5). This pattern indicates that the two assessments were overlapping in the variance accounted for in later borderline features. However, only childhood behavior could be assessed prospectively, because detailed interviews concerning experiences of parental abuse are difficult to administer prior to young adulthood. It is notable, then, that as early as age 8 , observed child behavior captured the variance in later symptoms associated with childhood abuse. 


\subsubsection{Assessment of later quality of interaction as mediator of effects of} earlier interaction-The fifth aim was to evaluate whether maternal withdrawal in infancy predicted borderline symptoms primarily because early maternal withdrawal led to child disorganized-controlling behavior at age eight, or whether these assessments of interaction at different developmental periods contributed independently to the prediction of borderline symptoms. A mediational model of borderline symptoms was tested in which maternal withdrawal in infancy was the independent variable and disorganized/controlling behavior in middle childhood was the proposed mediator. As noted earlier, maternal withdrawal had a significant total effect on later borderline symptoms (Table 3). This effect remained significant when prediction in later symptoms associated with disorganizedcontrolling behavior was removed ( $\beta=0.40, t=3.06, P=0.003)$, which suggests a lack of mediation. Bootstrapped confidence intervals confirmed that the indirect effect of maternal withdrawal on borderline symptoms through disorganized/controlling behavior was not statistically significant because the confidence intervals contained zero (Table 4). Thus, early maternal withdrawal affected later borderline symptoms directly and not through a relation to disorganized-controlling behavior in childhood.

\subsection{Observed interactions as predictors of suicidality/self-injury}

Because of the public health resources devoted to treating recurrent suicidality/self-injury, it is also important to know whether the aspects of interaction associated with borderline symptoms in general are also associated with suicidality/self-injury in particular. Following the same analysis strategy as above, logistic regression analyses examined the contributions of the same set of parent-child assessments to the prediction of the dichotomous variable of suicidality/self-injury.

3.3.1. Clinical risk, attachment, and interaction in infancy-The set of seven infancy variables as a whole significantly predicted late adolescent suidicality/self-injury $\left(X^{2}(7)=21.55, p=0.03\right.$; Table 6$)$. Early clinically-judged risk was a marginally significant predictor of suicidality/self-injury (Table 6), and maternal withdrawal in infancy was a significant predictor of suicidality/self-injury (Table 6). Security of the infant's attachment behavior was only marginally significant as a predictor (Table 6). Thus, infancy predictors of suicidality/self-injury were similar to those for overall borderline symptoms.

\subsubsection{Assessment of abuse as mediator of the effect of early maternal} withdrawal-In contrast to overall borderline symptoms, the effect of abuse on suicidality was not significant (Table 6). Thus, it was unlikely that early withdrawal affected suicidality through its relation to abuse. Bootstrapped confidence intervals confirmed that the indirect effect of withdrawal on suicidality through severity of abuse was not significant (Table 4), leaving the direct effect from withdrawal to suicidality as the primary pathway of influence.

\subsubsection{Observed interaction in middle childhood-Also in contrast to overall} borderline symptoms, there was no significant relation between suicidality/self-injury and disorganized-controlling behavior at age 8 (Table 6). Thus, disorganized-controlling behavior in middle childhood was not evaluated further, either in relation to effects of abuse or as a mediator of the effect of early maternal withdrawal on later recurrent suicidality/selfinjury.

\subsection{Exploratory analysis of subtypes of infant disorganization}

Based on the strength of prediction from maternal withdrawal, one additional exploratory analysis was undertaken. In previous publications (e.g. Lyons-Ruth et al., 1999), maternal withdrawal was associated with a specific subtype of disorganized infant behavior, the pseudo-secure subtype, in which the infant actively continues to seek contact with the 
mother while also showing odd, out-of-context behaviors. Other more intrusive forms of maternal behavior were associated with a different subtype of disorganization, in which the infant shows avoidant or ambivalent behavior around contact with mother, as well as odd, out-of-context behavior. Using the same linear or logistic regression format as above, the relation of each disorganized subtype to overall borderline symptoms and to suicidality/selfinjury was tested by entering the two dummy-coded subtype variables on the last step of the analysis. The pseudo-secure subtype was a specific predictor of suicidality at age 20 (Wald $=4.82, P=0.03)$, but not of overall borderline symptoms $(t=1.58, P=0.12)$. The avoidant/ ambivalent subtype, which was predictive of aggressive behavior at ages 5 and 7 (LyonsRuth et al., 1993; Lyons-Ruth et al., 1997), was not predictive of either borderline symptoms or suicidality (BPD symptoms $t=-0.47, P=.64$; Suicidality Wald $=1.77, P=0.18$ ). As exploratory analyses, these need replication. They are important, however, in suggesting the possibility of an early joint withdrawing mother/contact-seeking infant profile that confers risk for suicidality/self-injury in late adolescence.

\section{Discussion}

The first aim of this study was to assess whether disturbed parent-child interaction in infancy was predictive of borderline symptoms and suicidality/self-injury in late adolescence. Results indicate that maternal withdrawal in infancy predicts both borderline symptoms in general, and suicidality/self-injury in particular, almost 20 years later. In addition, early maternal withdrawal was an important mediator of the prediction available from clinician's judgments of risk, which adds to the ecological validity of the laboratory observations. These results provide support for the speculations of a number of theorists that aspects of parent-child interaction may be disturbed in some of the pathways leading to borderline personality disorder and suicidality/self-injury. However, these results add a level of specificity not contained in prior formulations. Both parental invalidation and attachment disturbances can take many forms, and only certain forms were related to borderline symptoms in the present study. Specifically, maternal withdrawing behavior to the infant's attachment cues was robustly related to later outcomes, while other forms of maternal behavior in infancy, including hostile and intrusive interactions, were not predictive of later symptoms. In the Carlson et al. (2009) study, by age three maternal hostility also became predictive, perhaps elicited by the toddler's increasing mobility and willfulness, but it was not a predictive factor here in infancy.

The second aim was to assess whether childhood abuse mediated the effect of early maternal withdrawal on adolescent outcomes. Results indicated that abuse experiences could not account for the independent effect of early maternal withdrawal on both borderline symptoms and suicidality/self-injury. This pattern of results suggests that to best account for borderline symptoms and suicidality, models need to include both abuse experiences and aspects of early parent-infant interaction.

By age 8 children who would later show borderline symptoms were more likely to display behavior toward the parent that combined punitive or caregiving elements with odd, inexplicable, disorganized behavior. Lyons-Ruth et al. (2007) also found that adult BPD patients were more likely than depressed patients to describe engaging in punitive or caregiving behavior toward a parent in childhood. These disorganized-controlling behaviors were further associated with abuse, and analyses indicated that there was important overlap in the variance in borderline features accounted for by these two assessments. Thus, disorganized-controlling behavior as early as age 8 may give us an important window onto seriously disturbed family relationships, before the child is able to report on familial abuse more freely. 
The final aim was to assess whether the emergence of child disorganized-controlling behavior by age 8 mediated the effect of early maternal withdrawal on later borderline symptoms. Results indicated that the later emergence of disorganized-controlling behavior could not account for the prediction available from early maternal withdrawal. This finding points to the continuing evolution of parent-child relationships from infancy to middle childhood and indicates the need for repeated parent-child assessments to fully account for the emergence of disorder. The results specifically do not support a "domino" model, in which disturbances in infancy determine specific subsequent developmental pathways.

Given the predictive strength of maternal withdrawal, however, research is needed to examine the biological consequences of early withdrawal for the infant's regulation of stressful arousal. Randomized animal models have shown that inattentive care in infancy can produce sustained enhancement of biological stress responses (Barr et al., 2003; Francis et al., 2003). Among human children, maternal withdrawal has also been associated with higher cortisol levels (Bugental et al., 2003). Since states of intense arousal characterize self-injuring individuals, the long-term prediction associated with maternal withdrawal may be mediated through effects on the child's stress response system.

We cannot judge, based on correlational data, whether disturbances in parent-child relations are child adaptations to disturbances in parenting or parental adaptations to emerging child disturbance or both. Given the links between borderline symptoms and genetic factors (Torgerson et al., 2000; Anguelova et al., 2003), it is possible that a more genetically reactive child temperament could lead to increased caregiver withdrawal, particularly if parents themselves are genetically vulnerable (White et al., 2003). The model that emerges is of a genetically stress-sensitive and contact-seeking infant coupled with a parent who withdraws from close contact, setting the stage for an escalating transactional process in which the infant's need for soothing may provoke parental withdrawal, which in turn increases the child's distress and need to involve and control the parent.

In other data from this cohort, antisocial personality disorder, which was more common among males, was predicted by maternal withdrawal in infancy and by disorganized (but not mixed disorganized and controlling) attachment behavior at age 8 (Shi et al., 2011). These results imply that deviations in the attachment relationship from infancy to age 8 may be part of a common environmental contribution to borderline and antisocial personality disorders, a contribution that in both cases was found to be independent of childhood abuse. Kendler et al. (2008), using behavioral genetic techniques, have also reported that ASPD and BPD share common (unspecified) environmental factors. In contrast, Bureau et al. (2009a) found that a different set of predictors contributed to prediction of depressive symptoms at age 20, including gender, maternal depressive symptoms in infancy, child depressive symptoms at age 8 , and maternal depressive symptoms in adolescence. Thus, there appears to be some specificity to the developmental pathways to Cluster B personality disorders compared to pathways toward later depression.

It was also notable that suicidality/self-injury alone had somewhat different developmental predictors than those associated with overall borderline features. Recurrent suicidality/selfinjury in late adolescence was more likely to have been preceded by clear (albeit disorganized) approach behavior toward mother when under stress in infancy, and was less likely to be associated with childhood abuse experiences and by disorganized-controlling behavior toward mother in middle childhood. Thus, we would speculate that when early parental withdrawal is not followed by later abusive experiences, the child is less likely to develop the controlling interpersonal style that foreshadows more general borderline features, while still being vulnerable to catastrophic suicidal or self-inuring reactions to 
experiences of interpersonal rejection (e.g. Klonsky, 2007). This possibility needs evaluation in future studies.

The current work is limited by the modest sample size and the small number who meet full diagnostic criteria. In addition, borderline symptoms in this cohort were primarily those of impulsive self-damaging behavior and suicidality, and results may be specific to such symptoms. Finally, participants were low income and contributors to impulsive, selfdamaging behavior may differ in higher income groups. Replication is needed in larger samples with a wider range of socioeconomic status.

In conclusion, the impulsive self-damaging behaviors examined here constitute wide-spread and costly public health problems that result in use of expensive emergency and inpatient services (e.g. Bender et al., 2001; Skodol et al., 2005). The early predictors identified here increase the possibility of identifying those at risk for self-damaging behavior earlier in the developmental process, before the incidence of such behavior begins to rise dramatically over the adolescent years (Kessler et al., 1999).

\section{Acknowledgments}

We would like to thank our most important collaborators, the families who have so generously given their time to this study. We would also like to acknowledge the invaluable contributions of many additional students and staff to the conduct of the study.

Funding

Supported by grants to Dr. Lyons-Ruth from the National Institute of Mental Health R01MH35122 and R01MH06030, the Smith-Richardson Foundation, the Borderline Foundation, and the Milton Fund of Harvard University and to Dr. Easterbrooks from Tufts University.

\section{References}

Ainsworth, MDS.; Blehar, MC.; Waters, E.; Wall, S. Patterns of attachment: A psychological study of the Strange Situation. Erlbaum; Hillsdale, NJ: 1978.

Allen B. An analysis of the impact of diverse forms of childhood psychological maltreatment on emotional adjustment in early adulthood. Childhood Maltreatment. 2008; 13(3):307-312.

American Psychiatric Association. Diagnostic and statistical manual of mental disorders. 4. APA; Washington, DC: 2000. text rev

Anguelova M, Benkelfat C, Turecki G. A systematic review of association studies investigating genes coding for serotonin receptors and the serotonin transporter: II. Suicidal behavior. Molecular Psychiatry. 2003; 8(7):646-653. [PubMed: 12874600]

Barr CS, Newman TK, Shannon C, Parker C, Dvoskin RL, Becker ML, Schwandt M, Champoux M, Lesch KP, Goldman D, Suomi SJ, Higley JD. Rearing condition and rh5-HTTLPR interact to influence limbic-hypothalamic-pituitary-adrenal axis response to stress in infant macaques. Biological Psychiatry. 2003; 55:733-738. [PubMed: 15039002]

Bender DS, Dolan RT, Skodol AE, Sanislow CA, Dyck IR, McGlashan TH, Shea MT, Zanarini MC, Oldham JM, Gunderson JG. Treatment utilization by patients with personality disorders. American Journal of Psychiatry. 2001; 158(2):295-302. [PubMed: 11156814]

Bernstein DP, Cohen P, Velez CN, Schwab-Stone M, Siever LJ, Shinsato L. Prevalence and stability of DSM-III-R personality disorder in a community-based survey of adolescents. American Journal of Psychiatry. 1993; 150:1237-1243. [PubMed: 8328570]

Bradley R, Jenei J, Westen D. Etiology of borderline personality disorder: Disentangling the contributions of intercorrelated antecedents. Journal of Nervous and Mental Disease. 2005; 193(1): 24-31. [PubMed: 15674131]

Brooks-Gunn, J.; Linver, MR.; Fauth, RC. Children's competence and socioeconomic status in the family and the neighbourhood. In: Elliot, AJ.; Dweck, CS., editors. Handbook of Competence and Motivation. Guilford Press; New York: 2005. p. 414-435. 
Bugental DP, Martorell GA, Barraza V. The hormonal costs of subtle forms of infant maltreatment. Hormones and Behavior. 2003; 43:237-244. [PubMed: 12614655]

Bureau J, Easterbrooks A, Lyons-Ruth K. Maternal depressive symptoms in infancy: Unique contribution to children's depressive symptoms in childhood and adolescence? Dev Psychopathol. 2009a; 21(2):519-537. [PubMed: 19338696]

Bureau J-F, Easterbrooks MA, Lyons-Ruth K. Attachment disorganization and role-reversal in middle childhood: Maternal and child precursors and correlates. Attachment, Human Development. 2009b; 11(3):265-284. [PubMed: 19455454]

Canli T, Lesch KP. Long story short: the serotonin transporter in emotion regulation and social cognition. Nature Neuroscience. 2007; 10(9):1103-1109.

Carlson EA. A prospective longitudinal study of attachment disorganization/disorientation. Child Development. 1998; 69:1107-1128. [PubMed: 9768489]

Carlson EA, Egeland B, Sroufe LA. A prospective investigation of the development of borderline personality symptoms. Development and Psychopathology. 2009; 21:1311-1334. [PubMed: 19825270]

Caspi A, Sugden K, Moffitt TE, Taylor A, Craig IW, Harrington H, McClay J, Mill J, Martin J, Braithwaite A, Poulton R. Influence of life stress on depression: Moderation by a polymorphism in the 5-HTT gene. Science. 2003; 301(5631):386-389. [PubMed: 12869766]

Cohen, J.; Cohen, P.; West, SG.; Aiken, LS. Applied multiple regression/correlation analysis for the behavioral sciences. Lawrence Erlbaum; Mahwah, NJ: 2003.

Cohen P, Chen H, Gordon K, Johnson J, Brook J, Kasen S. Socioeconomic background and the developmental course of schizotypal and borderline personality disorder symptoms. Development and Psychopathology. 2008; 20:633-650. [PubMed: 18423098]

Crawford TN, Cohen PR, Chen H, Anglin DM, Ehrensaft M. Early maternal separation and the trajectory of borderline personality disorder symptoms. Development and Psychopathology. 2009; 21:1013-1030. [PubMed: 19583895]

Dearing E, Hamilton LC. Contemporary advances and classic advice for analyzing mediating and moderating variables. Monographs of the Society for Research in Child Development. 2006; 71(3):88-104.

Dearing E, McCartney K, Taylor BA. Within-child associations between family income and externalizing and internalizing problems. Developmental Psychology. 2006; 42(2):237-252. [PubMed: 16569163]

Denham, SA. Emotional development in young children. Guilford Press; New York, NY: 1998.

Dutra, L.; Jenei, J.; Long, N.; Holmes, B.; Lyons-Ruth, K. Childhood traumatic experiences scale: Using the AAI to assess trauma. Poster session presented at the 21st Annual Meeting of the International Society for Traumatic Stress Studies; Toronto, Canada. 2005.

Fassler IR, Amodeo M, Griffin ML, Clay CM, Ellis MA. Predicting long-term outcomes for women sexually abused in childhood: Contribution of abuse severity versus family environment. Child Abuse and Neglect. 2005; 29(3):269-284. [PubMed: 15820543]

First, MB.; Gibbon, M.; Spitzer, RL.; Williams, JBW.; Benjamin, LS. User's guide for the structured clinical interview for DSM-IV Axis II personality disorders (SCID-II). American Psychiatric Press; Washington, DC: 1997a.

First, MB.; Spitzer, RL.; Gibbon, M.; Williams, JBW. Structured clinical interview for DSM-IV Axis I disorders-Clinical version (SCID-CV). American Psychiatric Press; Washington DC: 1997b.

Fonagy, P.; Gergely, G.; Jurist, EL.; Target, M. Affect regulation, mentalization and the development of the self. Other Press; New York: 2002.

Fonagy P, Luyten L. A developmental, mentalization approach to understanding and treatment of borderline personality disorder. Development and Psychopathology. 2009; 21:1355-1381. [PubMed: 19825272]

Francis D, Diorio J, Liu D, Meaney M. Nongenomic transmission across generations of maternal behavior and stress responses in the rat. Science. 1999; 286:1155-1158. [PubMed: 10550053]

Fruzzetti AE, Shenk C, Hoffman PD. Family Interaction and the development of borderline personality disorder. Development and Psychopathology. 2005; 17:1007-1030. [PubMed: 16613428] 
Gilks, WR.; Richardson, S.; Spiegelhalter, DJ. Markov Chain Monte Carlo in Practice. Chapman, Hall; London: 1996.

Grant BF, Chou SP, Goldstein RB, Huang B, Stinson FS, Saha TD, Smith SM, Dawson DA, Pulay AJ, Pickering RP, Ruan WJ. Prevalence, correlates, disability, and comorbidity of DSM-IV borderline personality disorder: results from the Wave 2 National Epidemiological Survey on Alcohol and Related Conditions. Journal of Clinical Psychiatry. 2008; 69:553-545.

Gross R, Olfson M, Gameroff M, Shea S, Feder A, Fuentes M, Lantigua R, Weissman MM. Borderline personality disorder in primary care. Archives of Internal Medicine. 2002; 162:53-60. [PubMed: 11784220]

Gunderson JG. The borderline patient's intolerance of aloneness: Insecure attachments and therapist availability. American Journal of Psychiatry. 1996; 153:752-758. [PubMed: 8633685]

Gunderson JG, Lyons-Ruth K. BPD's interpersonal hypersensitivity phenotype: A gene-environmentdevelopmental model. Journal of Personality Disorders. 2008; 22(1):22-41. [PubMed: 18312121]

Heath, N.; Schaub, K.; Holly, S.; Nixon, MK. Self-injury today: Review of population and clinical studies in adolescence. In: Nixon, MK.; Heath, NL., editors. Self-injury in youth: The essential guide to assessment and intervention. Routledge Press: New York, NY; 2009. p. 9-27.

Hertsgaard L, Gunnar M, Erickson MF, Nachmius M. Adrenocortical response to the strange situation in infants with disorganized/disoriented attachment relationships. Child Development. 1995; 66:1100-1106. [PubMed: 7671652]

Hesse E, Main M. Frightened, threatened, and dissociative parental behavior in low-risk samples: Description, discussion, and interpretations. Development and Psychopathology. 2006; 18:309_ 343. [PubMed: 16600057]

Horesh N, Ratner S, Laor N, Toren P. A comparison of life events in adolescents with major depression, borderline personality disorder, and matched controls: a pilot study. Psychopathology. 2008; 41:300-306. [PubMed: 18594165]

Johnson JG, Cohen P, Brown J, Smailes EM, Bernstein DP. Childhood maltreatment increases risk for personality disorders during early adulthood. Archives of General Psychiatry. 1999; 56:600-606. [PubMed: 10401504]

Kendler KS, Aggen SH, Czajkowski N, Roysamb E, Tambs K, Torgersen S, Neale MC, ReichbornKjennerud T. The structure of genetic and environmental risk factors for DSM-IV personality disorders: a multivariate twin study. Archives of General Psychiatry. 2008; 65:1438-1446. [PubMed: 19047531]

Kessler RC, Borges G, Walters EE. Prevalence of and risk factors for lifetime suicide attempts in the National Comorbidity Survey. Archives of General Psychiatry. 1999; 56(7):617-626. [PubMed: 10401507]

Klonsky ED. Non-suicidal self-injury: An introduction. Journal of Clinical Psychology. 2007; 63(11): 1139-1143.

Lenzenweger MF, Lane MC, Loranger AW, Kessler RC. DSM-IV personality disorders in the National Comorbidity Survey replication. Biological Psychiatry. 2007; 62:553-564. [PubMed: 17217923]

Levy KN. The implications of attachment theory and research for understanding borderline personality disorder. Development, Psychopathology. 2005; 17(4):959-986.

Lieb K, Zanarini M, Schmahl C, Linehan M, Bohus M. Borderline personality disorder. Lancet. 2004; 364:453-461. [PubMed: 15288745]

Linehan, MM. Cognitive-behavioural treatment of borderline personality disorder. Guilford Press; New York, NY: 1993.

Lyons-Ruth K, Bronfman E, Parsons E. Maternal frightened, frightening, or atypical behavior and disorganized infant attachment patterns. Monographs of the Society for Research in Child Development. 1999; 64:67-96. [PubMed: 10597543]

Lyons-Ruth K, Alpern L, Repacholi B. Disorganized infant attachment classification and maternal psychosocial problems as predictors of hostile-aggressive behavior in the preschool classroom. Child Development. 1993; 64:572-585. [PubMed: 8477635]

Lyons-Ruth, K.; Jacobvitz, D. Attachment disorganization: Genetic factors, parenting contexts, and developmental transformation from infancy to adulthood. In: Cassidy, J.; Shaver, PR., editors. 
Handbook of attachment: Theory, research, and clinical applications. Guilford; New York: 2008. p. 666-697.

Lyons-Ruth K, Melnick S, Patrick M, Hobson RB. A controlled study of hostile-helpless states of mind among borderline and dysthymic women. Attachment and Human Development. 2007; 9(1): 1-16. [PubMed: 17364479]

Madigan S, Bakermans-Kranenburg M, van Ijzendoorn M, Moran G, Peterson D, Benoit D. Unresolved states of mind, anomalous parental behavior, and disorganized attachment: A review and meta-analysis of a transmission gap. Attachment and Human Development. 2006; 8:89-111. [PubMed: 16818417]

Main M, Cassidy J. Categories of response to reunion with the parent at age six: predictable from infant attachment classifications and stable over a one-month period. Developmental Psychology. $1988 ; 24: 415-426$.

McCartney K, Burchinal M, Bub K. Best practices in quantitative methods for developmentalists. Monographs of the Society for Research in Child Development. 2006; 71(3):1-150. [PubMed: 17199773]

Moss E, Cyr C, Bureau JF, Tarabulsy GM, Dubois-Comtois K. Stability of attachment during preschool period. Developmental Psychology. 2005; 41(5):773-783. [PubMed: 16173874]

Moss E, Smolla N, Cyr C, Dubois-Comtois K, Mazzarello T, Berthiaume C. Attachment and behavior problems in middle childhood as reported by adult and child informants. Development and Psychopathology. 2006; 18(2):425-444. [PubMed: 16600062]

NICHD Early Child Care Research Network. Child-care and family predictors of preschool attachment and stability from infancy. Developmental Psychology. 2001; 37:847-862. [PubMed: 11699758]

Norris FH. Screening for traumatic stress: A scale of use in the general population. Journal of Applied Social Psychology. 1990; 20:1704-1718.

O'Connor E, Bureau J-F, McCartney K, Lyons-Ruth K. Risks and outcomes associated with disorganized/controlling patterns of attachment at age three in the NICHD study of early child care and youth development. Infant Mental Health Journal. 2011; 32(4):450-472. [PubMed: 21799549]

Preacher KJ, Hayes AF. Asymptotic and resampling strategies for assessing and comparing indirect effects in multiple mediator models. Behavior Research Methods. 2008; 40(3):879-691. [PubMed: 18697684]

Ross S, Heath N. A study of the frequency of self-mutilation in a community sample of adolescents. Journal of Youth and Adolescence. 2002; 31:67-77.

Rubin, DB. Multiple imputation for nonresponse surveys. Wiley; New York: 1987.

Schafer JL, Graham JW. Missing data: Our view of the state of the art. Psychological Methods. 2002; 7:147-177. [PubMed: 12090408]

Shi Z, Bureau JF, Easterbrooks MA, Zhao X, Lyons-Ruth K. Childhood maltreatment and prospectively observed quality of early care as predictors of antisocial personality disorder. Infant Mental Health Journal. 2011; 33:1-14.

Skodol AE, Gunderson JG, McGlashan TH, Dyck IR, Stout RL, Bender DS, Grilo CM, Shea T, Zanarini MC, Morey LC, Sanislow CA, Oldham JM. Functional impairment in patients with schizotypal, borderline, avoidant, or obsessive-compulsive personality disorder. American Journal of Psychiatry. 2002; 159:276-283. [PubMed: 11823271]

Skodol AE, Gunderson JG, Yen S, Stout RL, Morey LC, Sanislow CA, Grilo CM, Zanarini MC, McGlashan TH. Stability of functional impairment in patients with schizotypal, borderline, avoidant, or obsessive-compulsive personality disorder. Psychological Medicine. 2005; 35:443451. [PubMed: 15841879]

Soloff PH, Lynch KG, Kelly TM. Childhood abuse as a risk factor for suicidal behavior in borderline personality disorder. Journal of Personality Disorders. 2002; 16(3):201-214. [PubMed: 12136678]

Spangler G, Grossmann K. Biobehavioral organization in securely and insecurely attached infants. Child Development. 1993; 64:1439-1450. [PubMed: 8222882]

Stiglmayr CE, Shapiro DA, Stiegliz RD, Limberger MF, Bohus M. Experience of aversive tension and dissociation in female paitnets with borderline personality disorder - a controlled study. Journal of Psychiatric Research. 2001; 35(2):111-118. [PubMed: 11377440] 
Straus MA, Hamby SL, Boney-McCoy S, Sugarman DB. The revised Conflict Tactics Scales (CTS2): Development and preliminary psychometric data. Journal of Family Issues. 1996; 17:283-316.

Straus MA, Hamby SL, Finkelhor D, Moore DW, Runyan D. Conflict Tactics Scales: Development and psychometric data for a national sample of American parents. Child Abuse and Neglect. 1998; 22(4):249-270. [PubMed: 9589178]

Torgersen S, Kringlen E, Cramer V. The prevalence of personality disorders in a community sample. Archives of General Psychiatry. 2001; 58(6):590-596. [PubMed: 11386989]

Torgersen S, Lygren S, Oien PA, Skre I, Onstad S, Edvardsen J, Tambs K, Kringlen E. A twin study of personality disorders. Comprehensive Psychiatry. 2000; 41(6):416-425. [PubMed: 11086146]

van IJzendoorn M, Schuengel C, Bakermans-Kranenburg M. Disorganized attachment in early childhood: Meta-analysis of precursors, concomitants, and sequelae. Development and Psychopathology. 1999; 11(2):225-249. [PubMed: 16506532]

Widom CS, Czaja SJ, Paris J. A prospective investigation of borderline personality disorder in abused and neglected children followed up into adulthood. Journal of Personality Disorders. 2009; 23(5): 433-446. [PubMed: 19817626]

White CN, Gunderson JG, Zanarini MC, Hudson JI. Family studies of borderline personality disorder: A review. Harvard Review of Psychiatry. 2003; 11(1):8-19. [PubMed: 12866737]

Zanarini MC, Frankenburg FR, DeLuca CJ, Hennen J, Khera GS, Gunderson JG. The pain of being borderline: Dysphoric states specific to borderline personality disorder. Harvard Review of Psychiatry. 1998; 6(4):201-207. [PubMed: 10370445]

Zanarini MC, Williams AA, Lewis RE, Reich DB, Vera SC, Marino MF, Levin A, Yong L, Frankenburg FR. Reported pathological childhood experiences associated with the development of borderline personality disorder. American Journal of Psychiatry. 1997; 154:1101-1106. [PubMed: 9247396] 


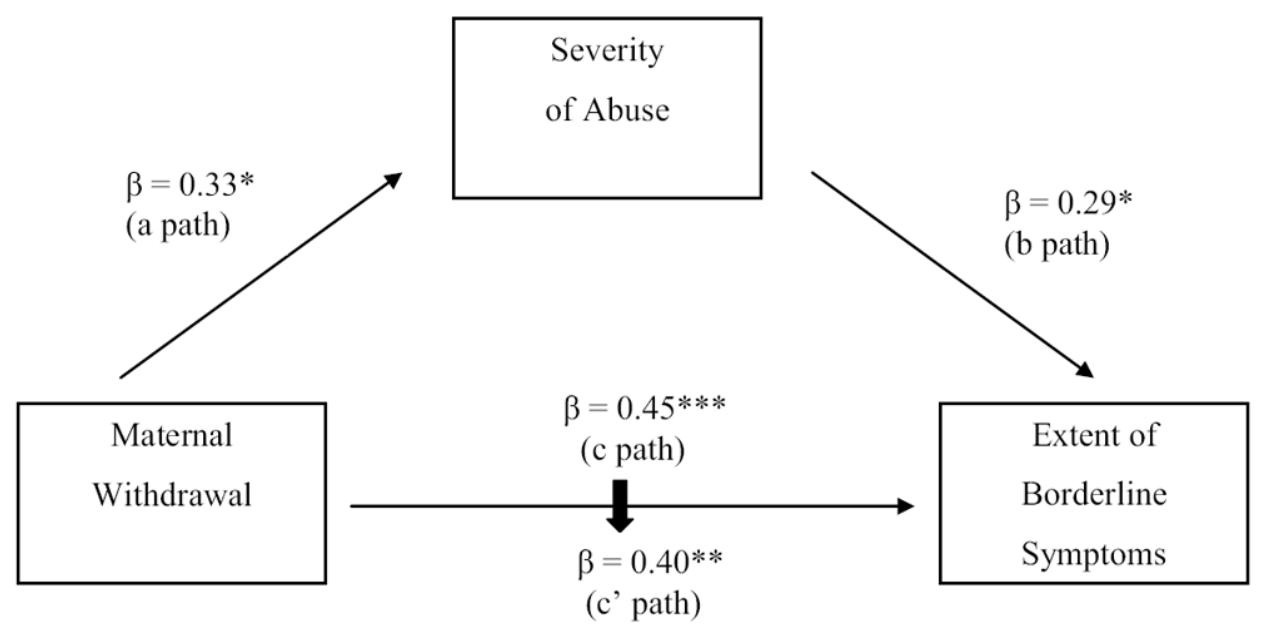

Figure 1.

Severity of Abuse Does Not Mediate the Effect of Early Maternal Withdrawal on Later Borderline Symptoms. 
Table 1

Descriptive Data for Study Variables

\begin{tabular}{llll}
\hline Longitudinal Subsample & & & \\
\hline Continuous variables & Mean & S.D. & Range \\
\hline Security of infant attachment (18 mos.) & 2.25 & .90 & $1-3$ \\
Maternal disrupted communication (18 mos.) & & & \\
$\quad$ Affective communication errors & 5.20 & 4.68 & $0-20$ \\
$\quad$ Role confusion & 5.10 & 7.35 & $0-27$ \\
$\quad$ Disorientation & 3.05 & 3.72 & $0-14$ \\
$\quad$ Negative intrusiveness & 2.37 & 3.71 & $0-16$ \\
$\quad$ Withdrawal & 3.21 & 3.55 & $0-15$ \\
Child disorganized-controlling behavior (8 yrs.) & 2.24 & .69 & $1-3$ \\
Severity of childhood abuse & 2.90 & 1.70 & $1-7$ \\
\hline Categorical variables & Percentages & & \\
\hline Gender (\% female) & $41.1 \%(23)$ & & \\
Presence of adolescent depression & $19.6 \%(11)$ & & \\
Protective service involvement (0-18 months) & $14.3 \%(8)$ & & \\
Early clinical risk (18 months) & & & \\
$\quad$ Not clinically referred-longitudinal & $48.2 \%(27)$ & & \\
Clinically referred-longitudinal & $51.8 \%(29)$ & & \\
\hline
\end{tabular}

Note. $N=56$ 


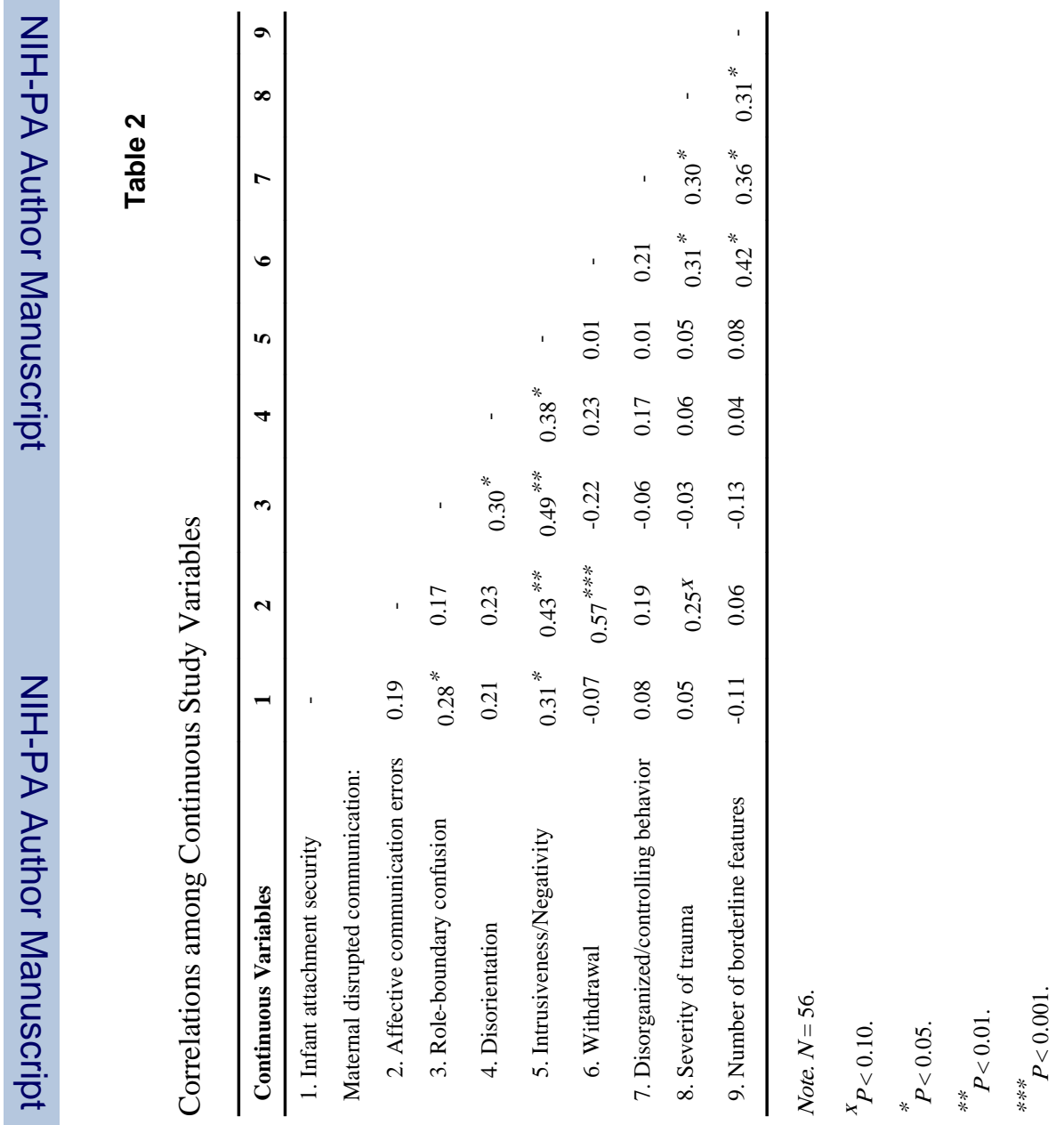


Table 3

Linear Regression Models Predicting Extent of Borderline Symptoms from Infancy and Childhood Assessments

\begin{tabular}{|c|c|c|c|c|}
\hline Predictor & $\beta$ & t-ratio & $d f$ & $p$ \\
\hline \multicolumn{5}{|l|}{ Parent-infant interaction $(18 \text { mos. })^{a}$} \\
\hline Early clinical risk & 0.27 & $2.07^{*}$ & 1,53 & 0.04 \\
\hline Infant attachment security $b$ & 0.05 & -0.40 & 1,53 & $n s$ \\
\hline \multicolumn{5}{|l|}{ Maternal disrupted communication: } \\
\hline Affective communication errors & 0.04 & 0.68 & 1,53 & $n s$ \\
\hline Role confusion & 0.08 & -0.54 & 1,53 & $n s$ \\
\hline Disorientation & 0.05 & 0.35 & 1,53 & $n s$ \\
\hline Negative-intrusiveness & 0.13 & 0.91 & 1,53 & $n s$ \\
\hline Withdrawal & 0.45 & $3.47^{* * *}$ & 1,53 & 0.001 \\
\hline \multicolumn{5}{|l|}{ Middle childhood attachment ( 8 yrs.) } \\
\hline Disorganized-controlling behavior & 0.33 & $2.31^{*}$ & 1,53 & 0.02 \\
\hline \multicolumn{5}{|l|}{ Childhood abuse to age 18} \\
\hline Severity of abuse & 0.29 & $2.31^{*}$ & 1,53 & 0.02 \\
\hline
\end{tabular}

Note. $N=56$. Gender and adolescent depression controlled in all analyses; gender t-ratio $=0.68, n s$; depression t-ratio $=2.62, P<0.05$.

${ }^{a}$ Statistics for all seven infancy variables entered on one step, $F(7,46)=4.18^{* *}, P=0.007$.

$b$ The two-category contrast, disorganized vs not disorganized, was also non-significant, $t=0.46, n s$.

* $P<0.05$.

*** $P<0.01$.

**** $P<0.001$. 
Table 4

Indirect Effects of Predictor Variables on Borderline Symptoms and Suicidality/Self-injury through Proposed Mediators

\begin{tabular}{|c|c|c|c|c|}
\hline \multirow[b]{2}{*}{ Indirect Effects } & \multirow[b]{2}{*}{ Point Estimate (SE) } & \multicolumn{3}{|c|}{ Bootstrapped Bias Corrected and Accelerated 95\% CI } \\
\hline & & Lower & Upper & Mediation \\
\hline \multicolumn{5}{|l|}{ Predicting Borderline Symptoms } \\
\hline Clinical referral through maternal withdrawal & $0.45(0.26)$ & 0.06 & 1.14 & Yes \\
\hline Maternal withdrawal through severity of abuse & $0.02(0.03)$ & -0.04 & 0.09 & No \\
\hline $\begin{array}{l}\text { Maternal withdrawal through disorganized/controlling } \\
\text { behavior }\end{array}$ & $0.03(0.03)$ & -0.02 & 0.10 & No \\
\hline \multicolumn{5}{|l|}{ Predicting Suicidality/Self-injury } \\
\hline Maternal withdrawal through severity of abuse & $0.07(0.28)$ & -0.80 & 0.40 & No \\
\hline
\end{tabular}

Note. 1,000 bootstrap samples. Gender and major depression controlled. If the confidence intervals do not contain zero, the null hypothesis of lack of mediation is rejected. 


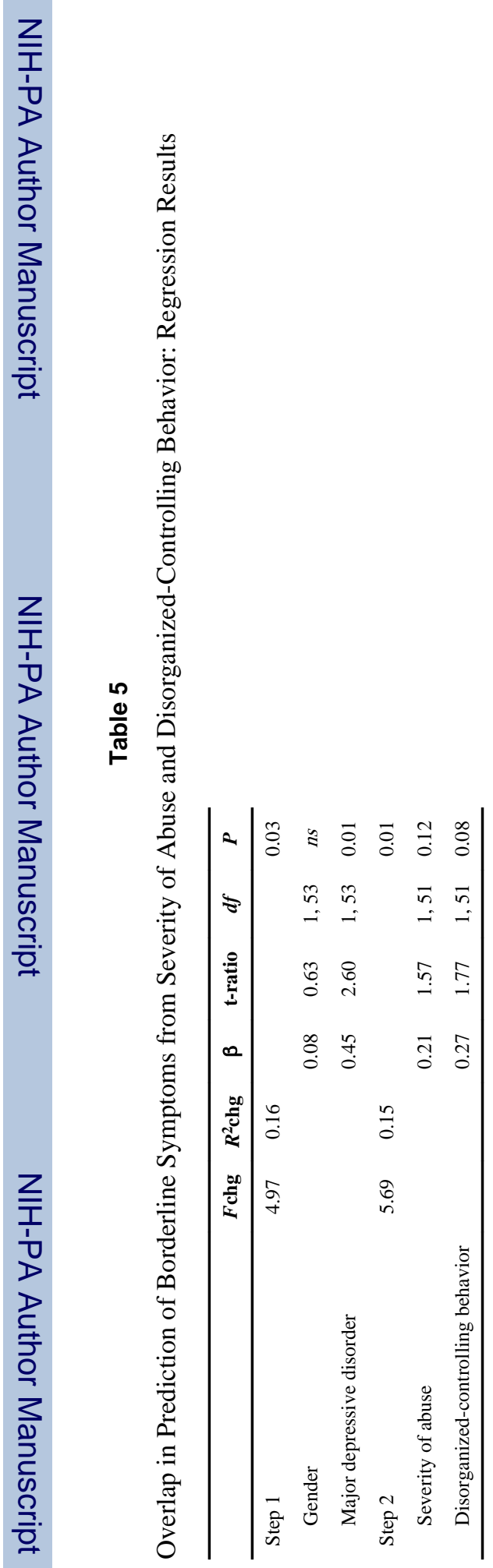

Psychiatry Res. Author manuscript; available in PMC 2014 April 30. 
Table 6

Logistic Regression Models Predicting Prevalence of Suicidality/Self injury from Infancy and Childhood Assessments

\begin{tabular}{|c|c|c|c|c|}
\hline Predictors & Wald & $d f$ & Odds ratio & $P$ \\
\hline \multicolumn{5}{|l|}{ Parent-infant interaction $(18 \mathrm{mos})^{a}$} \\
\hline Early clinical risk & $3.20^{X}$ & 1,53 & 2.15 & 0.07 \\
\hline Infant attachment security $b$ & 2.88 & 1,53 & 2.78 & 0.09 \\
\hline \multicolumn{5}{|l|}{ Maternal disrupted communication } \\
\hline Affective communication errors & 0.37 & 1,53 & 1.28 & 0.54 \\
\hline Role confusion & 0.21 & 1,53 & 0.80 & 0.65 \\
\hline Disorientation & 0.05 & 1,53 & 1.09 & 0.82 \\
\hline Negative-intrusiveness & 0.01 & 1,53 & 0.98 & 0.97 \\
\hline Withdrawal & $3.87^{*}$ & 1,53 & 2.17 & 0.05 \\
\hline \multicolumn{5}{|l|}{ Middle childhood attachment (8 yrs) } \\
\hline Disorganized-controlling behavior & 1.78 & 1,53 & 2.32 & 0.19 \\
\hline \multicolumn{5}{|l|}{ Childhood abuse to age 18} \\
\hline Severity of abuse & 1.44 & 1,53 & 1.62 & 0.23 \\
\hline
\end{tabular}

Note. $N=56$. Gender and adolescent depression controlled in all analyses; gender $X^{2}=0.23$, ns; depression $X^{2}=1.37$, ns.

${ }^{a}$ Statistics for all seven infancy variables entered on one step $X^{2}(7)=21.55, P=0.03$.

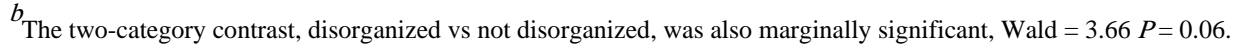

${ }^{X} P<0.10$.

* $P<0.05$.

*** $P<0.01$. 